\title{
¡Hasta siempre!
}

\author{
Juanjo Verdaguer
}

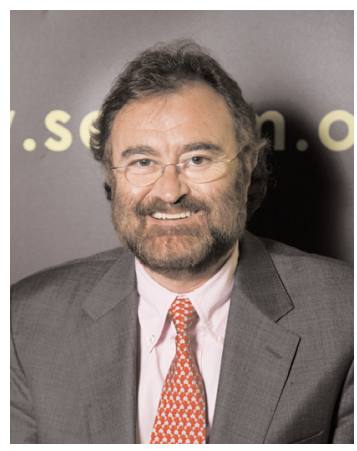

Hace dos décadas mi buen amigo Paco Alarcón, director por entonces de la revista Iberoamericana de Cirugía Oral y Maxilofacial, me llamó para que le ayudase en la edición de los números de la misma. Comenzó por entonces mi andadura en la Revista de la Sociedad que continuaría junto a mi, también amigo, Paco Díaz cuando recogió el testigo de su anterior director y modificó su nombre editorial e incrementó sus números anuales.

En 1993, al acceder al cargo de presidente de la S.E.C.O.M el Dr. Díaz González, me propuso ante la Junta Directiva para el cargo de director, al entender que era adecuado para el mismo, dado que llevaba años trabajando en la revista. Desde entonces hasta ahora los cambios en la edición de la misma son los que todos vosotros podéis ver y no procede enumerarlos uno a uno.

Durante estos catorce años como director me he rodeado de colaboradores muy valiosos, como ha sido en especial el Dr. Martín-Granizo, al que yo propuse como subdirector y fue aceptado por la Junta directiva de la Sociedad. Las relaciones con Jaime, director de la Editorial, junto a Rosi y Lucía, pilares fundamentales para la confección de los números, han sido muy buenas y fluidas, incluso aguantando número tras número las prisas que les daba para que saliesen en los plazos establecidos.

Cuando ya estaba prácticamente cerrado el trato para que las publicaciones incluidas en Scielo España pasasen automáticamente a indizarse en Medline, sucede el terrible atentado del $11 \mathrm{M} \mathrm{y...} \mathrm{todo} \mathrm{cambia.} \mathrm{Jorge} \mathrm{Veiga,} \mathrm{director}$ de la Biblioteca Nacional de Ciencias de la Salud, junto al director de Scielo y su equipo son sustituidos, resultado: nada de Index Medicus y un retraso de un año en la inclusión de los números de nuestra revista en la red. Esperemos que nuevos tiempos nos quiten la espinita que tenemos clavada desde hace tantos años en el corazón con el dichoso Index.

Quiero agradecer a todos los lectores de la revista y a los autores de artículos el cariño y comprensión que he recibido de ellos durante estos años, y mis más sinceras excusas si alguna vez les he podido molestar; asímismo, mi ánimo para el nuevo equipo de redacción. Como dice la famosa canción cubana del Comandante, ¡Hasta siempre! 